\title{
Baja incidencia de infección luego del aborto temprano
}

\author{
Low incidence of infection post early abortion
}

Trinder J. BMJ. 2006 May 27; 332 (7552):1235-1240.

\section{Objetivo}

Comprobar si existen diferencias significativas en la incidencia de infección ginecológica al comparar la conducta expectante (E) con el tratamiento médico (M) y el quirúrgico (Q) en el manejo del aborto del primer trimestre.

\section{Diseño}

Ensayo clínico aleatorizado y controlado.

\section{Lugar}

Estudio multicéntrico realizado en siete clínicas de embarazo temprano del Reino Unido.

\section{Pacientes}

Mujeres con embarazo menor a 13 semanas y diagnóstico de aborto incompleto o muerte fetal o embrionaria temprana (huevo/feto muerto y retenido).

\section{Medición de resultados}

El punto final primario fue la documentación de infección a las dos semanas de producido el aborto; y los secundarios infección a las ocho semanas, número de ingresos hospitalarios y legrados no planeados.

\section{Intervención}

1200 mujeres aleatorizadas en tres grupos (E: 399; M: 398 y Q: 403). El grupo $E$ no recibió una intervención específica; el $M$ recibió una dosis vaginal de misoprostol (las mujeres con muerte fetal temprana recibieron 24 a $48 \mathrm{~h}$ antes una dosis oral de mifepristone) y al grupo $Q$ se le realizó legrado.

\section{Resultados principales}

No se encontraron diferencias en la incidencia de infecciones a los 14 días ni a las ocho semanas del aborto. Ver tabla 1.

Tabla 1: diferencias en los resultados entre las diferentes conductas para el manejo del aborto del primer trimestre.

\begin{tabular}{|c|c|c|c|}
\hline & Expectante & Quirúrgica & Médica \\
\hline Incidencia de infección a & $3 \%$ & $2,8 \%$ & $2 \%$ \\
\hline $\begin{array}{l}\text { los } 14 \text { días y reducción del } \\
\text { riesgo absoluto (IC95\%) }\end{array}$ & \multicolumn{2}{|c|}{$\begin{array}{c}\text { Quirúrgico vs. expectante } 0,2 \\
(-2,2 \% \text { a } 2,7 \%)\end{array}$} & $\begin{array}{c}\text { Quirúrgico vs. médico } 0,8 \% \\
(-1,6 \% \text { a } 3,1 \%)\end{array}$ \\
\hline
\end{tabular}

Comparado con los resultados obtenidos en el grupo $Q$, el número de internaciones no planeadas fue 41\% (IC95\%: 36 a 47) mayor en el grupo $E$ y un $10 \%$ mayor (IC95\%: 6 a 15) en el M. Lo mismo ocurrió al comparar con el grupo $Q$ el número de mujeres que tuvieron un legrado no planeado, que fue un $39 \%$ (IC95\%: 44 a 34) mayor en el E y un 7,6\% (IC95\%: 3,6 a 11,7) en el $\mathrm{M}$.

\section{Conclusiones}

Las infecciones ginecológicas tienen baja incidencia luego de cualquier tipo de manejo del aborto del primer trimestre, sin diferencias significativas entre las tres estrategias evaluadas. Sin embargo, la estrategia quirúrgica parece asociarse a menor incidencia de internaciones y legrados no planeados.

Palabras clave: aborto-infección-procedimiento quirúrgico ginecológico. Key words: abortion-infection-surgycal gynecologic procedure.

Fuente de financiamiento: Instituto Nacional de Salud de Gran Bretaña.

\section{Comentario}

Si bien la conducta tradicionalmente más aceptada luego del aborto del primer trimestre es el legrado quirúrgico, este estudio demuestra que no está avalada por una disminución del riesgo de infección. Sin embargo, esta conducta parece implicar una menor incidencia de internaciones y legrados no planeados, y un menor tiempo de sangrado, sin diferencias en los valores de hemoglobina al día 14, y una menor necesidad de uso de analgésicos. Estas consideraciones, así como la posibilidad de que las pacientes se sientan más contenidas en un ambiente hospitalario ${ }^{1}$ y prefieran una estrategia que se asocie a menos sangrado y dolor, hace que la conducta quirúrgica tradicional sea la de mayor aceptación ${ }^{2}$. De todas maneras, cabe destacar que un tercio de las mujeres elegibles rehusaron participar del estudio, por lo que las inferencias que pueden realizarse de este trabajo son necesariamente limitadas debido a este sesgo de selección*.

\section{Conclusiones de la comentadora}

La elección del método a utilizar para lograr la evacuación uterina luego del aborto incompleto dependerá de las posibilidades de seguimiento de la paciente, de las preferencias personales y de los recursos del sistema ${ }^{3}$, aunque la estrategia quirúrgica parece ser la de mayor aceptación.

Mercedes Mutchinick [ Servicio de Medicina Familiar y Comunitaria. Hospital Italiano de Buenos Aires. ]

Mutchinick Mercedes. Baja incidencia de infección luego del aborto temprano, independientemente del tipo de manejo. Evid. actual. práct. ambul; 10(5): 142, Sep-Oct.2007. Comentado de: Trinder J. et al.Management of miscarriage: expectant, medical, or surgical? Results of randomised controlled trial (miscarriage treatment (MIST) trial). BMJ. 2006 May 27;332 (7552):1235-1240 PMID: 16707509. Cita disponible en Internet: http://www.ncbi.nlm.nih.gov/sites/entrez?cmd=retrieve\&db=pubmed\&list_uids=16707509\&dopt=medline

\section{Referencias}

1. American College of Obstetricians and Gynecologists (ACOG). Medical management of abortion. Washington (DC): American College of Obstetricians and Gynecologists (ACOG); 2005 Oct. 12 p. (ACOG practice bulletin; no. 67). [79 references]

2. Bradley E, Hamilton-Fairley D. Managing miscarriage in early pregnancy assessment units. Hospital Medicine 1998;59: 451-6. 3. Guidelines and Audit Committee of the Royal College of Obstetricians and Gynaecologists. The management of early pregnancy loss: clinical green top guidelines. London:
RCOG, 2000. 